American Journal of Applied Sciences 8 (11): 1195-1201, 2011

ISSN 1546-9239

(C) 2011 Science Publications

\title{
An Ergonomics Study on Assembly Line Workstation Design
}

\author{
${ }^{1}$ Baba Md Deros, ${ }^{1}$ Nor Kamaliana Khamis, ${ }^{2}$ Ahmad Rasdan Ismail, \\ ${ }^{1}$ Haris Jamaluddin, ${ }^{1}$ Azmi Mat Adam and ${ }^{1}$ Sarudin Rosli \\ ${ }^{1}$ Department of Mechanical and Materials Engineering, \\ Faculty of Engineering and Built Environment, \\ University Kebangsaan Malaysia, 43600 Bangi, Selangor, Malaysia, \\ ${ }^{2}$ Faculty of Mechanical Engineering, University Malaysia Pahang, \\ 26600 Pekan, Pahang, Malaysia
}

\begin{abstract}
Problem statement: High demand for products in the manufacturing industry had driven the human workers to work faster and adapt to their un-ergonomically designed workstation. Some tasks at assembly workstations require human workers to stand for a prolonged period of time to assemble the products. Approach: This study was conducted at an automotive component manufacturer. Twenty full time workers working at the assembly line participated as subjects in this study. Observations were made and recorded with respect to working postures practiced while performing their assembly tasks. Subjects' anthropometric data and current workstations dimensions were measured to determine whether they were suitable or not to perform the assembly tasks. Results: The findings from this study showed that there were four types of awkward postures and anthropometric data mismatches that had contributed to Musculoskeletal Disorders (MSDs) problems, faced by the subjects. Conclusion: The findings from this study shows current assembly workstation at Company a need to be redesign to eliminate awkward postures and anthropometric mismatches to lower MSDs problem and improve productivity among assembly workers.
\end{abstract}

Key words: Awkward posture, workstation design, Musculoskeletal Disorders (MSDs), unergonomically, assembly workstations, assembly tasks, anthropometric data

\section{INTRODUCTION}

Occupations that require prolonged periods of standing have been associated with the increasing number of complaints caused by standing fatigue and development of Musculoskeletal Disorders (MSDs) (Macfarlane et al., 1997; Zander et al., 2004; Tissot et al., 2009; Nelson-Wong and Callaghan, 2010a; 2010b). Modifying the flooring is a common intervention to deal with the problems associated with prolonged standing. Zander et al. (2004) had applied this concept for standing workers by conducting a study on different types of flooring conditions.

Modification the workstation design is an alternative approach that can be used to overcome MSDs problems faced by standing workers. Normally, the primary concern in designing a workstation is focused on equipment performance and operating time. With respect to the physical design of an industrial workstation, four design dimensions that consist of: work height; normal and maximum reaches; lateral clearance and angle of vision; and eye height are very important (Kroemer, 2008). Deros et al. (2009) suggest the workstation designer to incorporate the users' anthropometrics data in specifying the appropriate dimensions for the workstation. The workstation may not be able to function effectively, if there are mismatches between the users' anthropometric data and workstation dimensions (Deros et al., 2009; Ghazilla et al., 2010).

A literature review on past researches showed that there are few studies conducted with respect to new workstation design to solve MSDs and ergonomic problems faced by standing workers performing the various tasks. For example, Sillanpaa et al. (2003) had designed and construct a new table for working with the microscope to reduce the MSDs risks among the workers. Meanwhile, Forde and Buchholz (2004) had conducted a research with respect to task contents and physical ergonomic risk factors in the construction industry. In addition, Udosen (2006) had created a

Corresponding Author: Baba Md Deros, Department of Mechanical and Materials Engineering,

Faculty of Engineering and Built Environment, Universiti Kebangsaan Malaysia, 43600 Bangi, Selangor, Malaysia 
systematic tool called Computer Aided Design of Workplace Assembly Layout (CADWORK). CADWORK can be applied to design and build a new workplace from scratch or modify any existing workplace assembly layout fed into it. The two main objectives of conducting workplace assessment using CADWORK is to reduce the product assembly time and to design a safer workplace.

\section{MATERIALS AND METHODS}

Subjects: Company is a motorcycle engine manufacturer, located at Klang Valley, Selangor, Malaysia. This company employs 300 fulltime workers. For the purpose of this study, observation was conducted at the sub assembly line, focusing at Station 3 as shown in Fig. 1. Basically, the production target for this line is between 700-750 pieces per day. The daily working hours for a normal shift is between 8.00 am until $5.30 \mathrm{pm}$. There are three break times: Morning, lunch and afternoon.

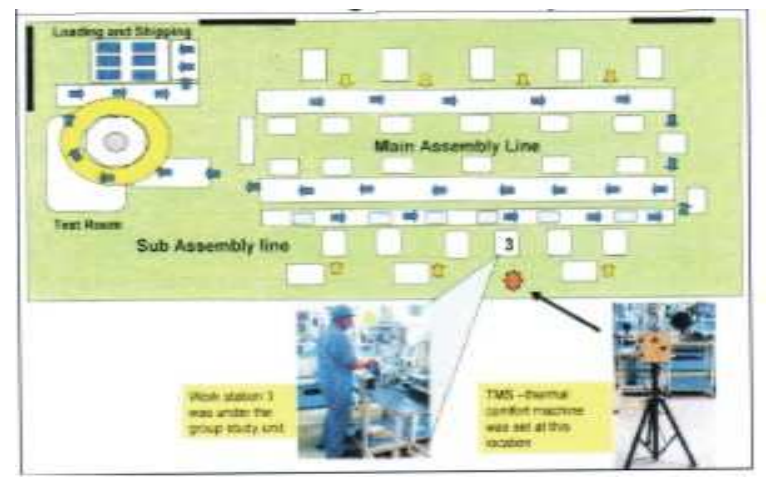

Fig. 1: Layout of workstation 3 for engine assembly line

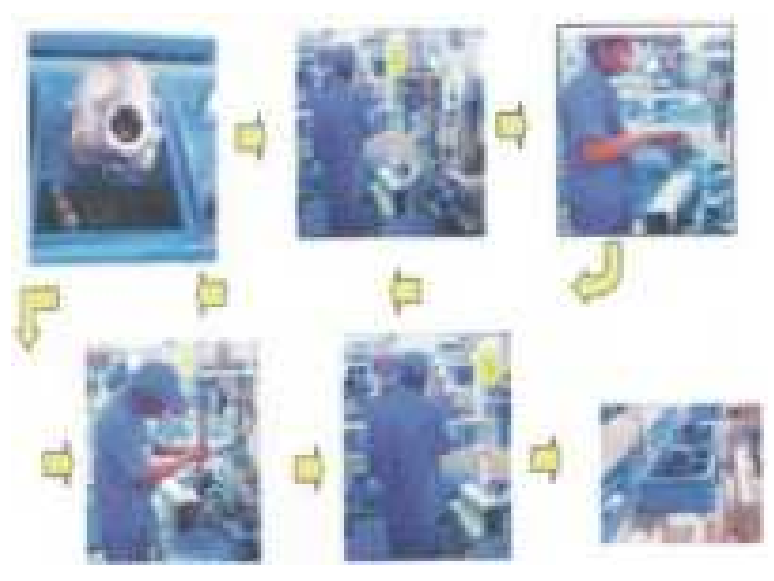

Fig. 2: Flow of the task at workstation 3
Twenty male assembly workers were chosen as subjects for this study. Their statures and elbow heights were measured and recorded. In addition, oral interviews were conducted with the workers at the workstations. The contents of oral interview with the workers includes: Work procedure; problems faced; and demographic background.

Study design: The main focus for this study is the movement and posture used while performing the assembly task. It was observed and recorded using video recorder. The two main benefits of using a video recorder are: the observer has a lot of time to view the movement and posture used by the subject; and it can easily be used to conduct a detailed analysis on the task performed (Ismail et al., 2009). It involved a few different activities that require the worker to perform the task while standing. Basically, the operator's task was to assemble two valves into the cylinder head. Figure 2 shows the steps and process flow for performing this task:

- The process starts when the cylinder head and valves arrived from previous process and ready for performing assembly process at Station 3

- The first movement is to pick up the cylinder head from a blue container and put it on the jig that act as a support on the press machine. Then, the operator will push the toggle switch to make the work piece to face straight upwards and ready for the pressing process

- Then, the operator will pick up the valves and put one of it into the cylinder head and placed the other one on the press jig

- When everything is ready at its place, the operator will press the green push button to start the pressing process for each valve

- After the second valve has been assembled the process is completed and the operator has to mark an indication at the cylinder head to confirm the final check has been done on the assembled parts

- Then remove the cylinder head from the jig and placed back onto the blue tray for the next station

\section{RESULTS}

The worker performs the task while in the standing position. He needs to complete a job with a standard time of 50 seconds or less. Normally, standing work is applied when the worker needs to make frequent 
movements in a large work area, handling heavy or large objects or exert large forces with their hands. In Company A, the workers' needs to performed four types of awkward postures while working at Station 3. Based on the results of oral interviews, neck pain and leg pain were reported as the two major MSDs complaints with respect to the task performed. After observing their activities, the authors found these pains were due to their workstation and task design that requires them to stand, to twist and bend their neck and bodies downwards.

Figure 3 shows the mean stature and elbow heights of the 20 subjects and the work surface of the workstation. These measurements were taken while the workers are performing their tasks. Basically, it covers the measurement from the head to the floor, the elbow to the floor, the height of the table and the visual angle.

Determination of workers stature and elbow heights: Referring to Table 1, there are twenty data for stature and elbow heights collected in this study.

Later, all the data was plotted on a normal distribution for the purpose of estimating the 5 and 95th percentiles values for stature and elbow height as shown in Fig. 4. The findings show that:

- The elbow height is between 95.12-110.91 cm with average of $103 \mathrm{~cm}$ and standard deviation is 4.78 ,

- The stature height is between $149.8-174.6 \mathrm{~cm}$ with average of $162 \mathrm{~cm}$ and standard deviation is $7.54 \mathrm{~cm}$.

Having done that, 5 and 95th percentile values found from this study ware compared with Malaysian anthropometric data compiled and developed by (Daruis et al., 2011; Deros et al., 2009). It was found that the values for the workers' stature and elbow heights lies within the acceptable ranges suitable for 90\% of Malaysian population anthropometric data. As highlighted by (Daruis et al., 2011; Deros et al., 2009). Malaysian anthropometric data for elbow height, 5 and 95th percentile is between $88.39-116.8 \mathrm{~cm}$ with the average $102.6 \mathrm{~cm}$ and the standard deviation $8.64 \mathrm{~cm}$. Meanwhile, the 5 and 95th percentile for stature is between $147.4-177.3 \mathrm{~cm}$ with the average $162.3 \mathrm{~cm}$ and the standard deviation $9.7 \mathrm{~cm}$.

Data comparison for standing work: Generally, the collected data fit with the Malaysian anthropometric data compiled (Daruis et al., 2011; Deros et al., 2009). It is recommended the table height need to follow the workers' mean elbow height with a plus minus $10 \mathrm{~cm}$ according to the type of jobs done on the table. Principally, the task performed in this study can be categorized as medium class light work. The recommended height of work benches is between $95 \mathrm{~cm}$ to $114 \mathrm{~cm}$. The measurement shows the current workbench height is $87 \mathrm{~cm}$ from the floor, which is too low. That is, it lies outside the range of recommended bench heights suitable for $90 \%$ of population data of elbow height taken from the subjects in the sub assembly line. As a result of this, the worker's needs to bend down while performing their work task. Figure 5 illustrated the comparison analysis of the workstation in the form of normal distribution.

\section{Recommendation on man-machine interface:} Figure 6 is the plan view of the work area and showed the worker had not reached the maximum recommended distance of $50 \mathrm{~cm}$ from the worker's body to the work piece. The body need to generate a higher force to the backbone as a result of higher torque being exerted while carrying the 1 kilogramme force when the load is located further away from the body. To complete the operation, the worker has to twist his backbone twice or 1500 times per day for output quantity of 750 pieces.

\begin{tabular}{lllll}
\multicolumn{5}{l}{ Table 1: } \\
$\begin{array}{l}\text { Stature, } \\
\mathrm{cm}\end{array}$ & $\begin{array}{l}\text { Elbow } \\
\text { height, } \mathrm{cm}\end{array}$ & $\begin{array}{l}\text { Subject } \\
\text { number }\end{array}$ & $\begin{array}{l}\text { Stature, } \\
\mathrm{cm}\end{array}$ & $\begin{array}{l}\text { Elbow } \\
\text { height, cm }\end{array}$ \\
\hline 167 & 106 & 11 & 157 & 100 \\
160 & 102 & 12 & 165 & 105 \\
161 & 102 & 13 & 155 & 98 \\
165 & 105 & 14 & 165 & 105 \\
160 & 102 & 15 & 156 & 99 \\
163 & 104 & 16 & 146 & 93 \\
154 & 98 & 17 & 182 & 116 \\
164 & 104 & 18 & 174 & 111 \\
158 & 100 & 19 & 165 & 105 \\
166 & 105 & 20 & 162 & 103 \\
\hline
\end{tabular}

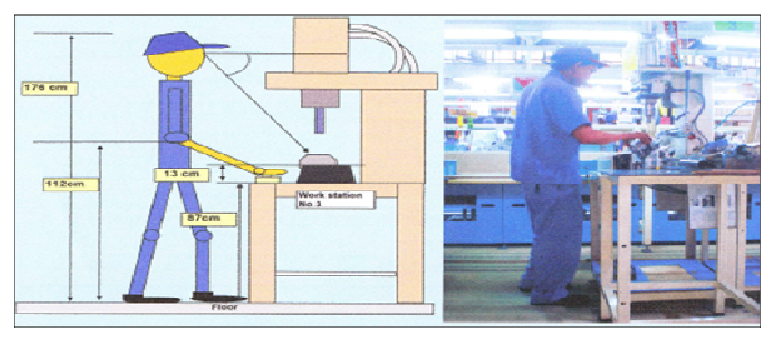

Figure 3: Standing work station 
Am. J. Applied Sci., 8 (11): 1195-1201, 2011

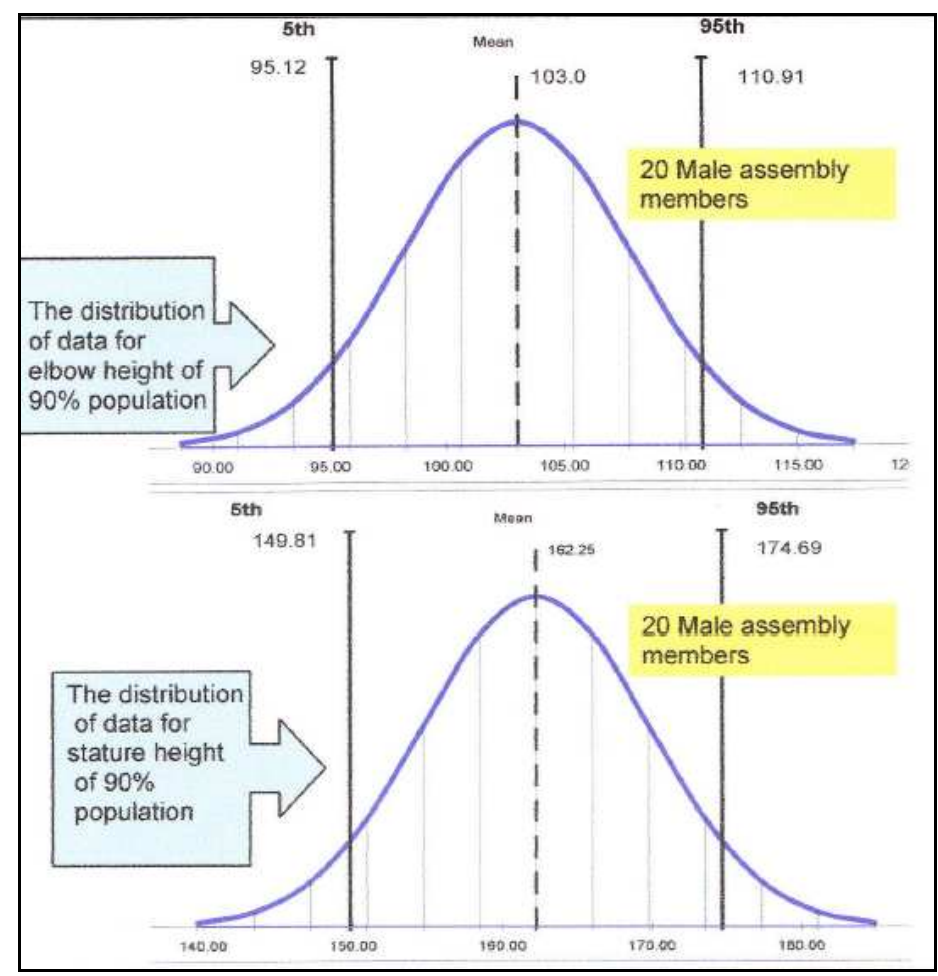

Figure 4: Normal distribution of 5 and 95th percentile for the stature and the elbow height

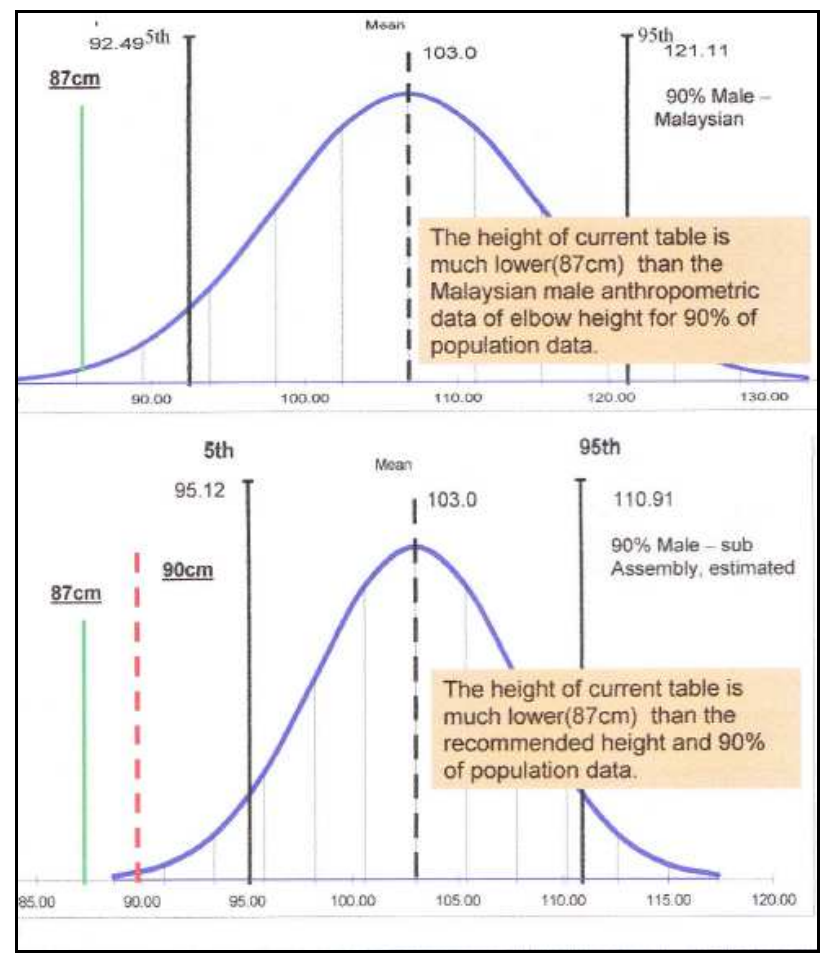

Fig. 5: Comparison of 5 and 95th percentile of population elbow height against existing workbench height 1198 


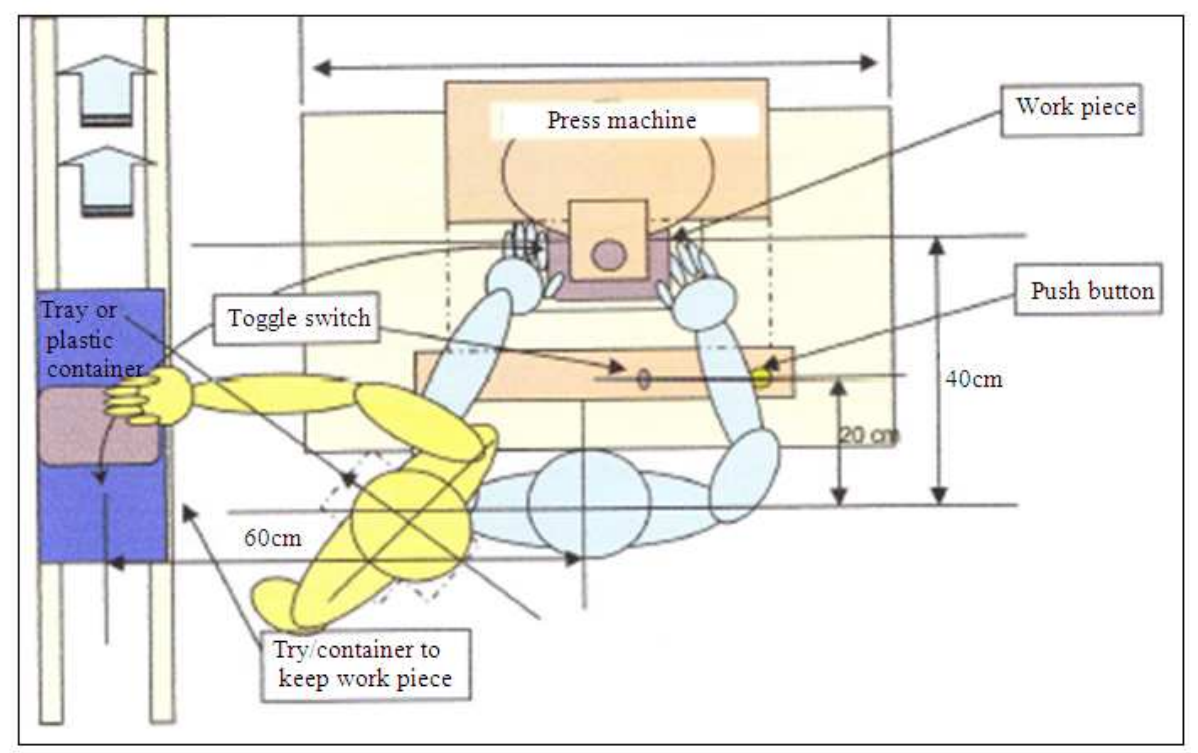

Fig. 6: A recommended plan view for the workstation

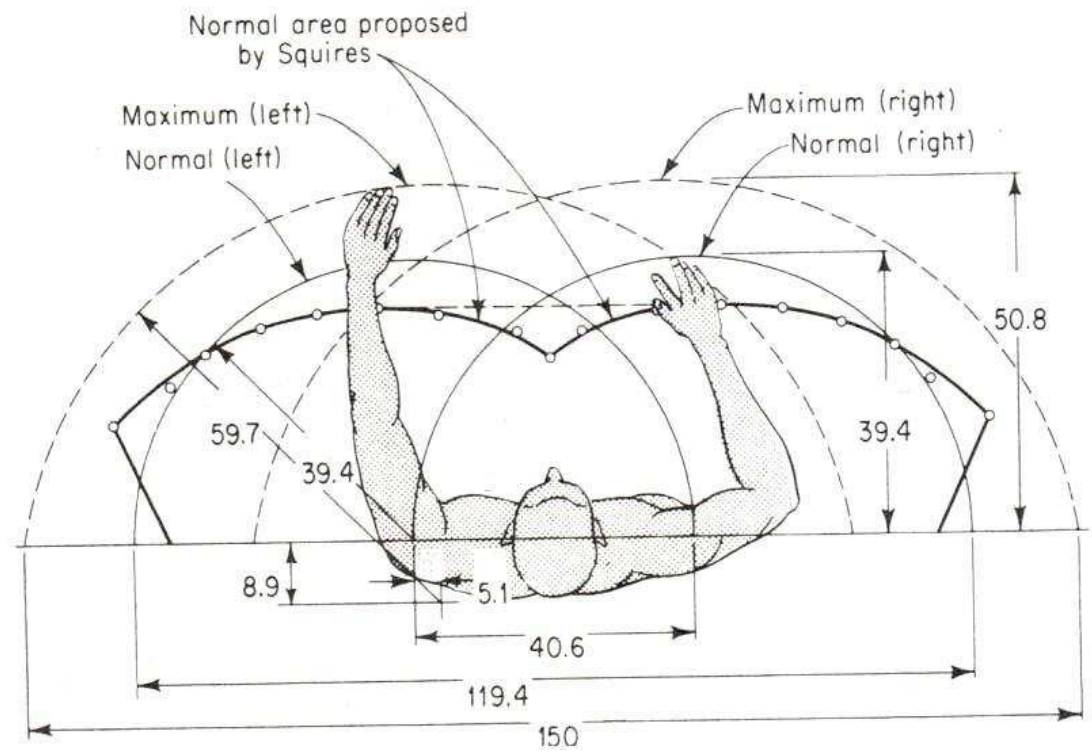

Fig. 7: Recommended working distance for the arms (Sanders and McCormick, 1993)

\section{DISCUSSION}

As a result, this situation will develop into Musculoskeletal Disorders (MSDs) problems to the worker as he carried 1 kilogramme work piece with his right hand. The visual angle is about 60 degrees downwards and requires the worker to bend his neck and spine when locating the valve to the fitting jigs. Fig. 6 illustrates a recommended plan view of the workstation.

Figure 7 illustrates the dimensions in centimetres of normal and maximum working areas in horizontal. Normal area is the area that can be conveniently reached with a sweep of the forearm while the upper arm hangs in a natural position at the side. Meanwhile, maximum area is the area that could be reached by extending the arm from the shoulder. 
The following are recommended working distance for the arms:

- Set the table height according to 5 and 95th percentile that is suitable for $90 \%$ of population elbow height with $95 \mathrm{~cm}$ as the minimum dimension as shown in Fig. 8.

- The worker should pick the cylinder head up with his left hand to avoid twisting of his spine, carry the load with two hands and move one or two steps to accommodate with the picking up and loading position

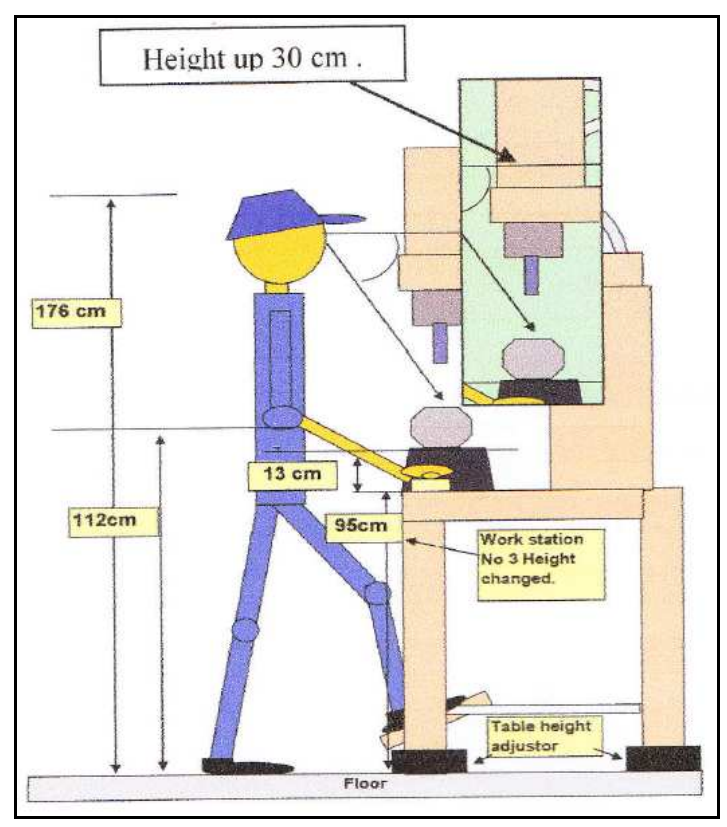

Fig. 8: A side-view of the recommended workstation

- Assign the worker with a height between 160$170 \mathrm{~cm}$ and elbow height $95-110 \mathrm{~cm}$. The objective is to avoid excessive pressure on the lumbar of the spinal column, if the worker is too short and to avoid bending posture when he is too tall

- Provide an adjustable table that can suit with any range of the workers' height

- Change the distance of support jig, so that it will be 20-30 cm away from the body

- Provide training and an instruction to guide the operator on assembling the valve without bending his neck and his backbone. Also, modify the jig to make it easier to fix and hook the valve

- Provide a footrest to avoid muscular strain or cramp
- Bring the table nearer to the rail to reduce the distance to carry the work piece and use left hand to avoid twisting of the body

- The work surface height should permit the upper arm and footrest in a relaxed position

- Visual angle should be maintained within 30 degrees at all times

\section{CONCLUSION}

This study had presented a case study conducted at an assembly workstation in at a motorcycle engine manufacturing company. In this company, the assembly workers perform most of their assembly tasks while in the standing position. The assembly tasks requires them to stand, bend their neck and body and twisting their spines. The findings from the case study indicate that the assembly workers had to use awkward postures while working with an un-ergonomically designed workstation. An appropriate workstation design is very critical in ensuring workers are safe and not exposed to musculoskeletal disorders problems due to mismatches between workers anthropometrics data with the tasks performed. In other words, a good workstation design that incorporated ergonomic principles could ensure workers' health and safety, while at the same time able to improve their productivity. In summary, workstation design needs to incorporate workers physical characteristics, working capabilities and limitations. It was found, the anthropometric data collected from 20 subjects at the Company $\mathrm{A}$ is still within the recommended range for the Malaysian population. However, there are some workstation parameters that need to be modified by the Company A to ensure their assembly workers are safe, comfortable and effective while using the workstation.

\section{REFERENCES}

Daruis, D.D.I., B.M. Deros and M.J.M. Nor, 2011. Malaysian sitting anthropometry for seat fit parameters. Human Factors Ergon. Manufact. Service Indus., 21: 443-455. DOI: $10.1002 / \mathrm{hfm} .20237$

Deros, B.M., D. Mohamad, A.R. Ismail, O.W. Soon and K.C. Lee et al., 2009. Recommended chair and work surfaces dimensions of VDT tasks for Malaysian citizens. Eur. J. Sci. Res., 34: 156-167. Forde, M.S. and B. Buchholz, 2004. Task content and physical ergonomic risk factors in construction ironwork. Int. J. Indus. Ergon., 34: 319-333 DOI: 10.1016/j.ergon.2004.04.011 
Ismail, A.R., M.L. Yeo, M.H.M. Haniff, R. Zulkifli and B.M. Deros et al., 2009. Assessment of postural loading among the assembly operators: A case study at Malaysian automotive industry. Eur. J. Sci. Res., 30: 224-235.

Kroemer, K.H.E., 2008. Fitting the Human: Introduction to Ergonomics. 6th Edn., CRC Press, Boca Raton, ISBN: 1420055399, pp: 437.

Macfarlane, G.J., E. Thomas, A.C. Papageorgiou, P.R. Croft and M.I. Jayson et al., 1997. Employment and physical work activities as predictors of future low back pain. Spine, 22: 1143-1149. PMID: 9160474

Ghazilla, R.A.R., Z. Taha, S. Kamaruddin and I. Hasanuddin, 2010. Pilot investigation on the mismatches of classroom furniture and student body dimensions in malaysian secondary schools. J. Soc. Sci., 6: 287-292. DOI: $10.3844 /$ jssp.2010.287.292

Sanders, M.S. and E.J. McCormick, 1993. Human Factors in Engineering and Design. 7th Edn., McGraw-Hill, USA., ISBN: 0071128263, pp: 790.

Sillanpaa, J., M. Nyberg and P. Laippala, 2003. A new table for work with a microscope, a solution to ergonomic problems. Applied Ergon., 34: 621-628. DOI: 10.1016/S0003-6870(03)00051-6
Tissot, F., K. Messing and S. Stock, 2009. Studying the relationship between low back pain and working postures among those who stand and those who sit most of the working day. Ergonomics, 52: 1402-1418. DOI: 10.1080/00140130903141204

Udosen, U.J., 2006. Ergonomic workplace construction, evaluation and improvement by CADWORK. Int. J. Indus. Ergonomics, 36: 219-228. DOI: 10.1016/j.ergon.2005.11.005

Nelson-Wong, E. and J.P. Callaghan, 2010a. The impact of a sloped surface on low back pain during prolonged standing work: A biomechanical analysis. Applied Ergon., 41: 787-795. DOI: 10.1016/j.apergo.2010.01.005

Nelson-Wong, E. and J.P. Callaghan, 2010b. Changes in muscle activation patterns and subjective low back pain ratings during prolonged standing in response to an exercise intervention, J. Electr. Kinesiol., 20: 1125-1133. PMID: 20674390

Zander, J.E., P.M. King and B.N. Ezenwa, 2004. Influence of flooring conditions on lower leg volume following prolonged standing. Int. J. Indus. Ergon., 34: 279-288. DOI: 10.1016/j.ergon.2004.04.014 